\title{
Analisis Kebijakan Program Rehabilitasi Sosial Penanganan Gelandangan Pengemis pada Dinas Sosial Kota Serang: Studi Peraturan Daerah Nomor 2 Tahun 2010
}

\author{
Vivi Anggraini Subu, Ida Hayu Dwimawanti dan Tri Yuniningsih \\ Faculty of Social Science and Political Science, Diponegoro University (50241), Indonesia \\ Email korepondensi: vivianggrainis07@gmail.com
}

\begin{abstract}
ABSTRAK
Gelandangan dan pengemis merupakan fenomena yang menjadi perhatian setiap daerah perkotaan di seluruh wilayah Provinsi, Indonesia. Peningkatan tertinggi pertumbuhan gepeng salah satunya di Provinsi Banten Ibu Kota Serang. Tersebar dan banyaknya gepeng menjadi pekerjaan rumah bagi pemerintah dalam memberikan penanganan yang sesuai, khususnya Dinas Sosial Kota Serang melalui program Rehabilitasi Sosial Penanganan Gelandangan Pengemis (gepeng). Tujuan dari penelitian untuk menganalisis keberhasilan dan mengidentifikasikan faktor pendorong dan penghambat keberhasilan program melalui (Perda Kota Serang Nomor 2 Tahun 2010 tentang Penyakit Masyarakat). Metode pengolahan data adalah metode analisis deskriptif kualitatif yang meliputi: reduksi data, penyajian data, verifikasi atau menarik kesimpulan. Berdasarkan hasil penelitian menunjukkan evaluasi program rehabilitasi sosial terhadap gepeng di Kota Serang yang dilakukan berdasarkan kriteria efektivitas, efesiensi, kecukupan, pemerataan, responsivitas, dan ketepatan sudah cukup baik dalam menangani permasalahan gepeng, namun terdapat beberapa hal penting yang harus di perbaiki dan ditingkatkan agar permasalahan gepeng di Kota Serang dapat diatasi. Untuk faktor pendorong program rehabilitasi sosial gepeng di Kota Serang, yaitu adanya dukungan Pemerintah baik melalui kebijakan/PERDA yang mengatur penangangan permasalahan gepeng. Kontribusi Pemerintah dalam bentuk support dana. Kordinasi aktif yang terjalin antar intansi yang terkait dalam rangka pembinaan gepeng, penertiban, dan penjaringan. Sedangkan faktor penghambat, anata lain: tidak adanya pendampingan secara berkala, kurangnya sosialisasi terkait program rehabilitasi sosial yang ada, komunikasi yang kurang baik antara petugas yang terkait dalam penjaringan, tidak adanya tindak lanjut dari Dinas Sosial ketika program selesai, kurangnya kesadaran gepeng untuk terlibat dalam kegiatan pembinaan, dan pelatihan dalam program rehabilitasi sosial yang diberikan.
\end{abstract}

Kata Kunci: Kemiskinan, Rehabilitasi Sosial, Evaluasi Kebijakan, Gepeng

\section{ABSTRACT}

Homeless and beggars are a problem that affects every metropolitan center in every part of the Province of Indonesia, and they are a source of worry for everyone. One of the places with the greatest rise in gepeng growth is Banten Province, which includes the capital of Serang. The government's task of providing proper management is complicated by the fact that gepeng are scattered and in large numbers. In particular, the Serang City Social Service, via the Social Rehabilitation program, is tasked with dealing with beggars and homeless persons (gepeng). The research aims to evaluate the program's performance and identify the elements that contributed to it and those that hindered it from being successful (Perda Kota Serang No. 2 of 2010 on Community Diseases). Methods such as data reduction, data presentation, verification, and generating conclusions are all part of a qualitative descriptive analysis technique, which comprises the following steps: According to the findings of the research, the 
evaluation of social rehabilitation programs against gepeng in Serang City is carried out based on the criteria of effectiveness, efficiency, adequacy, equalization, responsiveness, and accuracy, which is sufficient in dealing with the problem of gepeng. However, several important things must be improved and improved for the problem of gepeng to be resolved completely. According to the main driving force behind the social rehabilitation program in Serang City, namely the government's assistance, which comes in the form of regulations and PERDA that regulate the management of the gepeng issue. Contributions from the government in the form of financial assistance Gepeng, ordering, and networking are all aspects of the creation of gepeng that include active cooperation amongst linked diamonds. However, among the deterrents are the absence of periodic assistance, a lack of socialization related to existing social rehabilitation programs, poor communication between officers involved in networking, a lack of follow-up from social services after the program is completed, a lack of awareness to engage in coaching activities, and a lack of training in social rehabilitation programs provided, among other things.

Keywords: Poverty, Social Rehabilitation, Policy Evaluation, Gepeng

\section{PENDAHULUAN}

Problematika yang di hadapi oleh negara berkembang salah satunya masalah kemiskinan seperti Negara Indonesia, setelah kemerdekaan Indonesia seolah tidak dapat keluar dari persoalan kemiskinan yang mengalami sosial dilingkungan masyarakat. Data BPS menunjukkan jumlah penduduk miskin di Indonesia pada tahun 2020 sebesar 26,42 juta orang, yaitu mengalami peningkatan sebanyak 1,63 juta dibanding pada tahun 2019. (BPS.go,id, 2020)

Kemiskinan yang terjadi disebabkan oleh faktor yang berkaitan satu sama lainya yang di digolongkan menjadi dua model. Pertama bersifat struktural, disebabkan oleh perencanaan atau dampak dari suatu kebijakan menyebabkan masyarakat miskin tidak memiliki kekuatan untuk mengubah kehidupan dan hidup dalam kemiskinan secara berkelanjutan. Kedua bersifat kultural, disebabkan adanya faktor internal dari masyarakat yang menjadi suatu kebiasaan untuk tidak senantiasa melakukan aktualisasi diri mengakibatkan banyak program pemerintah atau model pemberdayaan yang berikan tidak berpengaruh untuk mengubah masyarakat tersebut (Fadri, 2019). Menurut Siahaan (2004) dalam (Fadri, 2019) kemiskinan kultural disebabkan oleh sikap seseorang atau masyarakat yang tidak mau berusaha untuk memperbaiki diri menjadi lebih baik karena kebiasaan atau budaya yang dilakukan secara terus - menerus.

Menurut (Zefianningsih, Wibhawa, \& Rachim, 2016) keterbatasan untuk memenuhi kebutuhan disebabkan karena pendidikan yang rendah dan tidak adanya ruang gerak bagi mereka untuk berkreasi dan berinovasi. penelitian lain yang mendukung menurut (Rina Rohmaniyati, 2016) faktor penyebab kemiskinan antara lain mempunyai keterbatasan secara fisik maupun mental, kurangnya keterampilan dan malas berusaha, pendidikan yang rendah serta minimnya ketersediaan lapangan kerja. Hal ini berkaitan dengan ketenagakerjaan yang berdampak munculnya penggangguan atau tuna karya. Data BPS Pusat menunjukan tahun 2020 jumlah pengangguran di Indonesia sebesar 9,77 juta orang dengan kenaikan sebesar 7,07 persen atau mengalami kenaikan sebesar 2,67 juta orang pada periode yang sama di tahun 2019. Permasalahan ini dapat menimbulkan masalah sosial lainya, yaitu munculnya gelandangan dan pengemis atau biasa disebut Gepeng.

Provinsi Banten dengan ibu Kota Serang merupakan salah satu provinsi di Indonesia dengan pertumbuhan gepeng yang tak terkendali. Pada tahun 2019 jumlah pengemis di Provinsi Banten sebesar 581 orang sedangkan jumlah gelandangan di tahun yang sama sebesar 324 orang. Sedangkan Untuk tingkat pengangguran di Kota Serang pada tahun 2020 sebesar 12,22 
persen atau sebesar 72.584 orang. Kota Serang memiliki kampung yang dijuluki sebagai “Kampung Pengemis" karena masyarakat disana pada umumnya berofesi sebagai pengemis. Lokasi kampung berada tidak jauh dari jantung Kota Serang, yaitu Kampung Kebanyakan, Kelurahan Sukawana, Kecamatan Serang, Kota Serang, Banten.

Pemerintah Kota Serang telah mempunyai peraturan daerah sebagai upaya pemberantasan gepeng, peraturan daerah tersebut diatur dalam PERDA Kota Serang Nomor 2 tahun 2010 Tentang Pencegahan, Pemberantasan Dan Penanggulangan Penyakit Masyarakat. Dalam pelarangan kegiatan gepeng peraturan tersebut tertuang pada pasal 9 ayat (1), (2), dan (3). Pemerintah Kota Serang melarang kepada masyarakatnya untuk tidak menjadi gelandangan dan pengemis, dilarang pula untuk memaksa orang lain untuk mengemis, serta dilarang untuk yang memberikan uang ataupun lainnya kepada pengemis. Bagi yang melanggar peraturan tersebut seperti yang dijelaskan pada pasal 21 ayat (1) dengan ancaman hukuman pidana dan denda.

Fakta dilapangan PERDA ini tidak memiliki kekuatan untuk menghentikan laju pertumbuhan gepeng di Kota Serang. Gepeng yang telah terjaring dan diberikan pencerahan serta penjelasan tentang pelarangan kegiatannya berdasarkan pada PERDA yang berlaku tidak dapat menghentikan kegiatannya itu, mereka cenderung bertambah jumlahnya dan para gepeng sering sekali ditemukan di jalan-jalan, pusat perbelanjaan, rumah makan, alun-alun kota, tempat penziarahan, dan tempat-tempat yang menjadi pusat keramaian lainnyadi Kota Serang. Penelitian yang mendukung menurut (Ikmal, 2019) berkembangnya kelompok gelandangan dan pengemis (gepeng) dibeberapa tempat atau daerah termasuk fenomena sosial yang harus perhatian bersama.

Mengacu pada PERDA Kota Serang Nomor 2 Tahun 2010, Pemerintah Kota Serang telah membuat program melalui Dinas Sosial Kota Serang untuk menangani permasalahan gepeng. Program tersebut yaitu Rehabilitasi Sosial Gelandangan dan Pengemis. Program tersebut sebagai langkah yang dilakukan Pemerintah Kota Serang sebagai upaya untuk mengembalikan para gepeng agar dapat melaksanakan fungsi sosialnya kembali secara wajar dalam kehidupan masyarakat.

Program Rehabilitasi Sosial Gelandangan dan Pengemis diharapkan mampu menjadi alat untuk mengurangi dan menekan jumlah gepeng yang ada di Kota Serang. Program tersebut antara lain: (1) Program Pelayanan dan Rehabilitasi Kesejahteraan Sosial; (2) Program Pembinaan Anak Terlantar; (3) Program Pembinaan Para Penyandang Cacat dan Trauma; (4) Program Pembinaan Eks Penyandang Penyakit Sosial; (5) Program Pembinaan Panti Asuhan/ Panti Jompo; (6) Program Pemberdayaan Fakir Miskin; (7) Program Pelayanan dan Rehabilitasi Kesos; (8) Program Pemberdayaan Kelembagaan Sosial.

Setiap program yang dibuat pemerintah tentu memerlukan evaluasi di dalamnya untuk mengetahui sejauh mana program terlaksana atau adanya kendala yang harus dibenahi sehingga tujuan dari suatu program dapat tercapai. Menurut (Sudjana, 2008) evaluasi program yaitu pengidentifikasian keberhasilan atau kegagalan suatu kegiatan atau program yang telah terlaksana. Evaluasi program biasanya dilakukan untuk kepentingan pengambilan keputusan dalam rangka menentukan kebijakan selanjutnya.

Hasil penelitian yang dilakukan oleh (Nurkholis, 2017) menyatakan bahwa pencegahan, pemberantasan dan penanggulangan para gelandangan dan pengemis di Kota Serang khususya di daerah Pisang Mas belum terlaksana dengan baik serta tidak berjalan secara optimal. Sosialisasi yang dilakukan berdasarkan Perda No 2 Tahun 2010 belum berjalan optimal, masih terdapat masyarakat Kota Serang yang masih memberikan uang santunan kepada Gelandangan dan Pengemis yang sedang beraktivitas di Lampu Merah Pisang Mas Kota Serang. Satpol PP selaku pihak eksekutor jarang melakukan tindakan razia, ketidaktepatan sasaran serta tidak menyeluruhnya kegiatan penjangkauan razia terhadap gelandangan dan pengemis di Pisang 
Mas Kota Serang sehingga peran dan ketertiban Satpol PP dalam menertibkan gelandangan dan pengemis sangat minim dan terbatas.

Berdasarkan latar belakang di atas peneliti tertarik untuk melakukan evaluasi terkait pelaksanaan Program Rehabilitasi Sosial dalam menanggulangi Gelandangan Pengemis (Gepeng) Oleh Dinas Sosial Kota Serang serta mengevaluasi dampak program rehabilitasi sosial tersebut terhadap kehidupan gelandangan dan pengemis di Kota Serang.

\section{METODE PENELITIAN}

Penelitian ini dilaksanakan di Kota Serang, Provinsi Banten. Pemilihan lokasi penelitian ini dilakukan secara purposive dengan pertimbangan bahwa di Kota Serang terdapat satu kampung yaitu Kampung Kebanyakan, Desa Sukawan, Kota Serang, Banten yang sebagian besar masyarakatnya berprofesi sebagai pengemis sehingga kampung ini dijuluki "Kampung Pengemis" yang berlokasi di jantung Kota Serang yang merupakan ibu kota provinsi Banten yang seharusnya menjadi pusat pertumbuhan ekonomi di Provinsi Banten. Penelitian dilaksanakan selama 4 bulan terhitung mulai bulan Januari 2021 sampai Mei 2021.

Gambar 1. Peta Lokasi

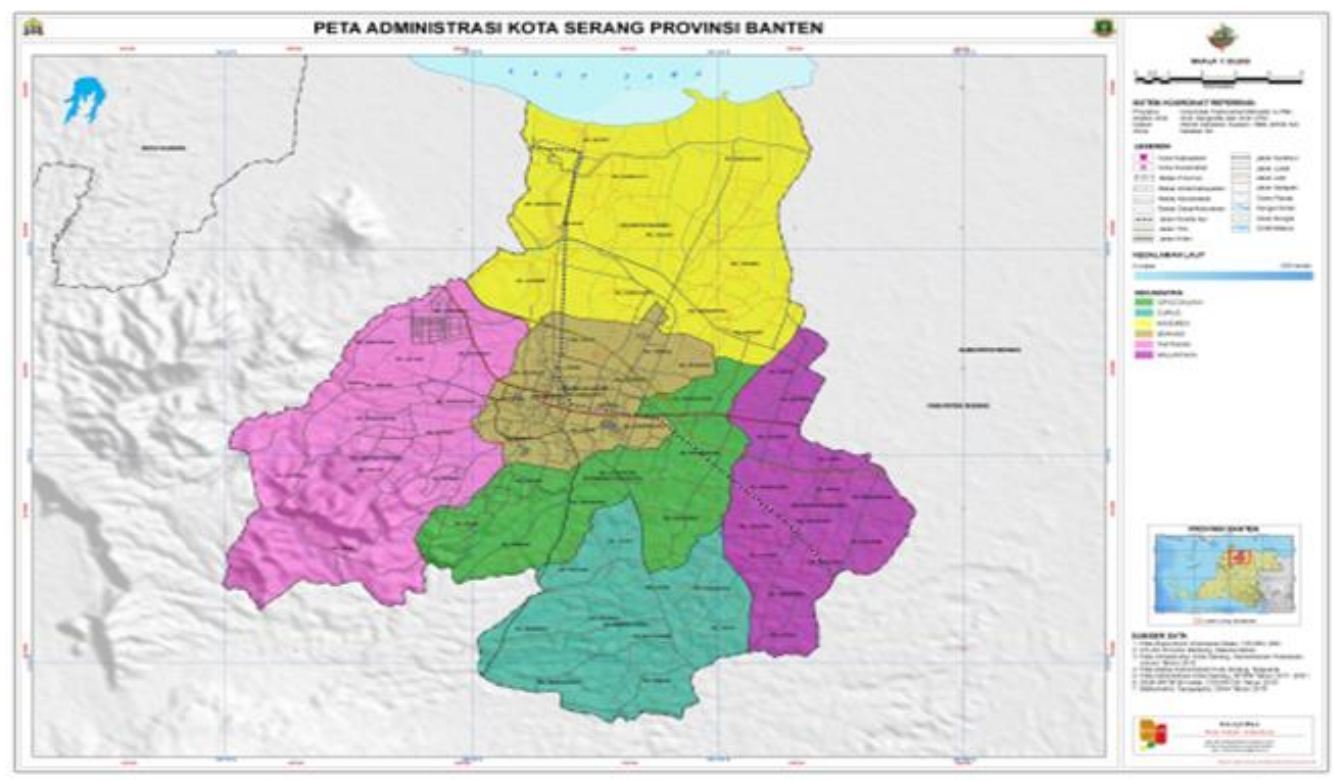

Source: BPS Kota Serang

Metode penelitian digunakan, yaitu metode analisis deskriptif kualitatif. Jenis dan sumber data penelitian terdiri dari data primer yang diperoleh dari hasil observasi lapangan dan wawancara mendalam dengan pihak-pihak terkait penelitian ini melalui teknik Purposive, mulai dari pengumpulan data sampai pengolahan data hasil penelitian, seperti Kabid Rehabilitasi Sosial, petugas Satpol PP, gelandangan, dan pengemis. Sedangkan data sekunder diperoleh dari dinas atau instansi terkait penelitian, Dinas Sosial Kabupaten Serang, serta BPS Kabupaten Serang. Teknik pengumpulan data penelitian ini terdiri dari indepth interview, observasi, studi dokumentasi

Metode pengolahan data dalam penelitian ini meliputi: reduksi data, yaitu dilakukan dengan cara menajamkan analisis, menggolongkan atau pengkategorisasian ke dalam tiap permasalahan melalui uraian singkat, mengarahkan, membuang yang tidak perlu, dan mengorganisasikan data sehingga dapat ditarik dan diverifikasi. Penyajian data, yaitu 
dipaparkan dalam bentuk uraian naratif, bagan, hubungan antar kategori serta diagram alur. Menarik kesimpulan atau verifikasi, yaitu untuk mencari atau memahami makna/arti, keteraturan, pola-pola, penjelasan (mencari hubungan diantara dimensi-dimensi yang diuraikan), dan alur sebab akibat atau proposisi. Setelah melakukan verifikasi maka dapat ditarik kesimpulan berdasarkan hasil penelitian yang uraikan dalam bentuk narasi. Penarikan kesimpulan merupakan tahap akhir dari pengolahan data.

\section{HASIL DAN PEMBAHASAN}

\section{Program Rehabilitasi Gelandangan dan Pengemis}

Tugas pokok Kepala Bidang rehabilitasi adalah membantu Kepala Dinas Sosial dalam melaksanakan pembinan, koordinasi, evaluasi dan perumusan kebijkan teknis operasional dibidang Rehabilitas Sosial. Program - program pelayanan dan rehabilitasi meliputi:
a) Program Pelayanan dan Rehabilitasi Kesejahteraan Sosial;
b) Program Pembinaan Anak Terlantar;
c) Program Pembinaan Para Penyandang Cacat dan Trauma;
d) Program Pembinaan Eks Penyandang Penyakit Sosial;
e) Program Pembinaan Panti Asuhan/ Panti Jompo;
f) Program Pemberdayaan Fakir Miskin;
g) Program Pelayanan dan Rehabilitasi Kesos;
h) Program Pemberdayaan Kelembagaan Sosial;

Tahapan - tahapan rehabilitasi sosial yang dilakukan oleh pihak Dinas Sosial Kota Serang sebagai berikut:

1. Melakukan Razia/Penjaringan tahap ini pihak Dinsos berkoordinasi dengan Satpol PP dalam melakukan penjaringan terhadap Gepeng yang berkeliaran di jalanan, kemudian akan diserahkan kepada pihak Dinsos untuk dilakukan tindakkan selanjutnya.

2. Asessmen tahapan ini pihak Dinsos melakukan identifikasi terhadap gepeng yang terjaring razia. Menggali informasi terkait latar belakang, asal dari mana, tempat tinggal, keluarga yang dibisa dihubungi, alasan menjadi gepeng, dan sebagainya.

3. Melakukan Seleksi tahapan ini dimana gepeng yang telah di asesmen akan diseleksi kembali oleh pihak Dinsos. Masalah gepeng yang terjaring bukan penduduk Kota Serang atau pendatang dari luar provinsi, maka pihak Dinsos akan menghubungi Dinsos yang bersangkutan dan berkoordinasi untuk pemulangan gepeng ke tempat asalanya menggunakan mobil gratis yang disediakan oleh Dinsos Kota Serang setelah mendapatkan persetujuan dari pihak Dinsos tujuan tempat asal gepeng. Sedangkan untuk gepeng yang terindikasi ODGJ (Orang Dalam Gangguan Jiwa) langsung dibawa ke Yayasan Nururrohman Sawah Luhur Kecamatan Kasemen.

4. Penerimaan tahapan ini gepeng yang telah diseleksi dan dinyatakan layak untuk menerima pembinaan akan dikirim ke Rumah Singgah Hasil Razia (RSHR). Selanjutnya gepeng akan didampingi pihak Dinsos melakukan registrasi, pemeriksaan kesehatan, serta pemeriksaan kebersihan.

5. Pembinaan tahap ini gepeng yang telah terdaftar akan diberi pelatihan keterampilan yang mencakup pelatihan perbengkelan, tata boga dan wira usaha. Gepeng juga akan diikutsertakan dalam seminar - seminar pelatihan yang bekerjasama dengan lembaga pendidikan. Tujuan dari pelatihan untuk mendapatkan pengetahuan dan keterampilan serta perubahan sikap atau prilaku menjadi lebih baik. (Imsiyah, Wahono, Zulkarnain, Wahyuni, \& Hendrawijaya, 2020) dalam Mustofa (2010). Selama pembinaan gepeng juga diberi honorarium berupa uang saku. 
6. Penyaluran tahapan penayaluran meliputi serangkaian kegiatan yang diarahkan untuk mengembalikan gepeng kedalam kehidupan masyarakat secara normatif, baik di lingkungan keluarga maupun masyarakat setempat yang dilakukan oleh Pekerja Sosial.

\section{Evaluasi Program Rehabilitasi Gelandangan dan Pengemis}

Indikator-indikator keberhasilan yang harus dicapai dalam analisis evaluasi rehabilitasi sosial gelandangan dan pengemis di Kota Serang sebagai berikut:

1. Tidak ada lagi masyarakat Kota Serang yang menjadi Pengemis dan Peminta-minta

2. Tidak ada lagi anak jalanan dan gelandangan yang berkeliaran di lingkungan Kota Serang.

3. Masyarakat Kota Serang yang berasal dari kalangan pengemis dan gelandangan mendapatkan pembinaan dan pelatihan secara merata dan menyeluruh.

4. Terdapatnya masyarakat yang berasal dari kalangan pengemis dan gelandangan yang memiliki keterampilan khusus serta memiliki rasa percaya diri.

5. Munculnya usaha-usaha baru yang diperuntukkan bagi gelandangan dan pengemis sesuai dengan skill yang telah didapatkan.

6. Tingginya partisipasi masyarakat untuk turut serta bekerja sama dengan dinas sosial Kota Serang dalam memberdayakan gelandangan dan pengemis dengan menerima keberadaan mereka dan mempekerjakan mereka dengan keterampilan yang sesuai.

Keberhasilan program rehabilitasi sosial gelandangan dan pengemis di Kota Serang diukur menggunakan indikator keberhasilan menurut William Dunn mencakup efektivitas, efisensi, kecukupan, pemerataan, responsivitas, dan ketepatan.

\section{Efektivitas}

Efektivitas mengandung pengertian taraf tercapainya suatu tujuan tertentu, baik ditinjau dari segi hasil, maupun usaha dari segi usaha yang diukur. Hasil temuan di lapangan pelaksanaan program rehabilitasi sosial gelandangan dan pengemis di Kota Serang sudah cukup efektif dalam menangani permasalahan gepeng tetapi kendala yang dihadapi, yaitu kurangnya sosialisasi yang dilakukan sehingga program tersebut belum secara luas diketahui oleh para gepeng

\section{Efesiensi}

Kriteria efisiensi, yaitu menilai suatu kebijakan atau program mengenai seberapa banyak upaya yang diperlukan untuk mencapai hasil yang diinginkan. Menurut (Dunn, 2003) Efisiensi berkenaan dengan jumlah usaha yang diperlukan untuk dapat menghasilkan tingkat efektivitas yang dikehendaki. Kriteria efisiensi program rehabilitasi sosial gelandangan dan pengemis digunakan sebagai suatu usaha yang dilakukan oleh Dinas Sosial Kota Serang selaku pelaksana program Rehabilitasi Sosial Gelandangan dan Pengemis yang berkaitan dengan sumber daya yang dimiliki termasuk anggaran dana dan sumber daya manusia untuk mencapai tujuan yang telah ditetapkan.

Pemerintah juga mendorong keberhasilan program rehabilitasi sosial tersebut dengan memberikan anggaran dan dana hibah untuk meningkatkan fasilitas dan sarana yang ada di Rumah Singgah Hasil Razia serta menjembatani terjalinnya kerjasama antar Dinas Sosial dengan lembaga dan balai pelatihan yang bertujuan untuk membina para gepeng. Melalui kerjasama dengan lembaga dan instansi atau kedinasan menjadi faktor pendukung keberhasilan program rehabilitasi sosial tersebut dalam menangani permasalahan gepeng.

\section{Kecukupan}

Pengertian kecukupan dalam kebijakan publik dapat dikatakan tujuan yang telah dicapai sudah dirasakan oleh subjek penelitian itu sendiri. Berdasarkan penelitian mengenai program 
rehabilitasi sosial gelandangan dan pengemis di Kota Serang yang dilihat dalam indikator kecukupan bahwa peningkatan taraf hidup gepeng yang telah diberikan pembinaan dan pelatihan masih belum dirasakan oleh kebanyakan gepeng, dimana hanya segelintir gepeng yang menjadi mandiri dan berwirausaha ataupun bekerja dengan layak. Sedangkan gepeng yang lain hanya mengharapkan bantuan dari pemerintah. Dilihat dari segi perubahan sikap, perilaku, dan pola pikir bahwa program rehabilitasi sosial tersebut belum cukup mampu dalam mengubah sikap gepeng yang belum proaktif dan bertahan dengan keadaan yang ada tanpa ada inisiatif untuk berubah, sebagian dari mereka hanya mengharapkan bantuan dana dari pemerintah.

\section{Pemerataan}

Pemerataan dalam kebijakan publik dapat diartikan suatu keadilan yang diberikan dan diperoleh dari suatu kebijakan publik. Hasil dilapangan menunjukkan bahwa program rehabilitasi sosial gelandangan dan pengemis di Kota Serang berdasarkan aspek pemerataan belum sepenuhnya merata dan menyeluruh hal itu terjadi karena beberapa faktor baik eksternal maupun internal. Faktor internalnya disebabkan karena kurangnya kesadaran gepeng untuk dibawa dan dibina, sedangkan faktor eksternalnya bahwa kebanyakan gepeng bukan berasal dari Kota Serang melainkan dari luar provinsi seperti dari Palembang dan Lampung.

\section{Responsivitas}

Responsivitas dapat juga dikatakan respon dari suatu aktivitas. Menurut William N Dunn bahwa indikator responsivitas itu dilihat dari seberapa jauh kebijakan tersebut menjawab kebutuhan masyarakat (Dunn, 2000). Kriteria responsivitas melihat kesesuaian antara program pelatihan keterampilan dengan keinginan masyarakat ataupun kebutuhan masyarakat. Berdasarkan hasil penelitian dilapangan bahwa program rehabilitasi sosial sudah responsive, artinya program - program yang ada sudah sesuai dengan apa yang diharapkan oleh masyarakat, yaitu diberikan pelatihan keterampilan berupa perbengkelan, berwirausaha dan juga tata boga. Dengan harapan keterampilan yang telah dimiliki tersebut mampu di aplikasikan dalam kehidupan sehari - hari agar gepeng tidak lagi turun ke jalanan. Gepeng juga akan diberikan honor ketika pembinaan telah selesai dilakukan.

\section{Ketepatan}

Ketepatan merujuk pada kuatnya asumsi yang melandasi tujuan - tujuan tersebut. Tujuan program rehabilitasi sosial gelandangan dan pengemis ini adalah untuk mengurangi angka gepeng di Kota Serang. Berdasarkan tujuan tersebut, program rehabilitasi sosial yang telah dilaksanakan oleh Dinas Sosial sudah sesuai dengan tujuan dimana gepeng yang sudah dibina dan diberi pelatihan hanya sedikit yang kembali ke jalanan atau berhenti menjadi gepeng.

\section{Faktor - faktor Pendorong dan Penghambat Keberhasilan Program Rehabilitasi Sosial Gelandangan dan Pengemis}

Berdasarkan hasil evaluasi "program rehabilitasi sosial gelandangan dan pengemis di Kota Serang" terdapat faktor - faktor yang mempengaruhi keberhasilan dari program tersebut.

\section{Faktor Pendorong}

Faktor pendorong dalam mencapai keberhasilan dari program rehabiliasi sosial gelandangan dan pengemis di Kota Serang antara lain: (1) Perhatian dan dukungan pemerintah melalui kebijakan/perda yang mengatur penangangan permasalahan gepeng di Kota Serang; (2) Dukungan kerjasama atau kemitraan dengan lembaga, instansi, dan balai pelatihan dalam rangka pembinaan gepeng; (3) Koordinasi aktif antar Dinas Sosial Kota Serang dengan tingkat provinsi, kecamatan, dan Dinas Sosial di luar provinsi. (4) Partisipasi pemerintah daerah dalam 
bentuk support dana untuk memenuhi anggaran yang dibutuhkan dinas sosial; (5) Keterlibatan serta dukungan dari Satpol PP dalam melakukan penertiban dan penjaringan gelandangan dan pengemis di Kota Serang.

\section{Faktor Penghambat}

Faktor penghambat dalam mencapai keberhasilan dari program rehabilitasi sosial gelandangan dan pengemis di Kota Serang antara lain: (1) Tidak adanya pendampingan secara berkala yang dilakukan oleh pihak dinsos atau pekerja sosial kepada para gepeng yang telah selesai dibina;

(2) Kurangnya sosialisasi oleh Pemerintah Kota Serang dan Dinas Sosial terkait program rehabilitasi sosial yang ada; (3) Komunikasi yang kurang baik antara petugas Satpol PP dengan para gepeng sehingga gepeng lebih memilih kabur; (4) Tidak adanya tindak lanjut dari Dinas Sosial ketika program telah selesai dilakukan; (5) Kurangnya kesadaran gepeng untuk terlibat dalam kegiatan pembinaan dan pelatihan dalam program rehabilitasi sosial yang ada.

\section{KESIMPULAN}

Berdasarkan hasil dan pembahasan mengenai evaluasi program rehabilitasi sosial terhadap gelandangan dan pengemis di Kota Serang dapat dirumuskan kesimpulan sebagai berikut:

1. Hasil analisis evaluasi program rehabilitasi sosial terhadap gelandangan dan pengemis di Kota Serang yang dilakukan berdasarkan kriteria penilaian menurut William Dunn bahwa pada kriteria efektivitas, efesiensi, kecukupan, pemerataan, responsivitas dan ketepatan, program rehabilitasi sosial gelandangan dan pengemis di Kota Serang sudah cukup baik dalam menangani permasalahan gepeng namun terdapat beberapa hal penting yang harus di perbaiki dan ditingkatkan agar permasalahan gepeng di Kota Serang dapat diatasi.

2. Faktor - fakor keberhasilan program rehabilitasi sosial gelandangan dan pengemis di Kota Serang dipengaruhi oleh 2 faktor, yaitu: (1) faktor pendorong, antara lain: Perhatian dan dukungan pemerintah melalui kebijakan/perda yang mengatur penangangan permasalahan gepeng; dukungan kerjasama dengan berbagai instansi dan balai pelatihan dalam rangka pembinaan gepeng; kordinasi aktif yang terjalin antar Dinas Sosial Kota Serang dengan kecamatan atau di luar provinsi; partisipasi pemerintah daerah dalam bentuk support dana untuk memenuhi anggaran yang dibutuhkan; dan adanya keterlibatan serta dukungan dari Satpol PP dalam melakukan penertiban dan penjaringan gelandangan dan pengemis di Kota Serang. (2) faktor penghambat, anata lain: tidak adanya pendampingan secara berkala kepada para gepeng yang telah selesai dibina; kurangnya sosialisasi terkait program rehabilitasi sosial yang ada; komunikasi yang kurang baik antara petugas Satpol PP dengan para gepeng sehingga gepeng lebih memilih kabur; tidak adanya tindak lanjut dari Dinas Sosial ketika program telah selesai dilakukan; kurangnya kesadaran gepeng untuk terlibat dalam kegiatan pembinaan dan pelatihan dalam program rehabilitasi sosial yang ada.

\section{DAFTAR PUSTAKA}

Dunn. (2000). Pengantar Analisis Kebijakan Publik Edisi Kedua. Yogyakarta: Gajah Mada University Press, 13-26.

Dunn, W. (2003). Analisa Kebijakan Publik. Yogyakarta: PT. Prasetia Widia Pratama, 2(1), $119-128$.

Fadri, Z. (2019). Upaya Penanggulangan Gelandangan Dan Pengemis (Gepeng) Sebagai Penyandang Masalah Kesejahteraan Sosial (Pmks) Di Yogyakarta. Komunitas, 10(1), 119. https://doi.org/10.20414/komunitas.v10i1.1070 
Ikmal, M. (2019). Kebijakan Pemenuhan Hak Sosial dan Politik Gepeng - Moh. Ikmal. Jurnal Ilmiah Manajemen Publik Dan Kebijakan Sosial, 3(1), 327-341. Retrieved from https://ejournal.unitomo.ac.id/index.php/negara/article/view/1901

Imsiyah, N., Wahono, Zulkarnain, Wahyuni, S., \& Hendrawijaya, A. T. (2020). Empowerment of Homeless and Beggars Through Education and Training, 501(Icet), 282-286. https://doi.org/10.2991/assehr.k.201204.053

Nurkholis, H. (2017). Implementasi PERDA Kota Serang Tahun No. 2 Tahun 2010 Tentang Pencegahan, Pemberantasan dan Penanggulangan Penyakit Masyarakat, (2).

Rina Rohmaniyati. (2016). Vagrants and Beggars Empowerment Through Economic Productive Efford Activities In Social Institution Hafara, Bantul, Daerah Istimewa Yogyakarta. Jurnal Pendidikan Luar Sekolah.

Sudjana, D. (2008). Evaluasi Program Pendidikan Luar Sekolah. Bandung: PT Remaja Rosdakarya, 2(2000), 2017-2018.

Zefianningsih, B. D., Wibhawa, B., \& Rachim, H. A. (2016). Penanggulangan Gelandangan Dan Pengemis Oleh Panti Sosial Bina Karya "Pangudi Luhur" Bekasi. Prosiding Penelitian Dan Pengabdian Kepada Masyarakat, 3(1). https://doi.org/10.24198/jppm.v3i1.13600 